\title{
BRAKING NEWS: An experimental study of language attitudes towards improper and proper spelling perceived as misspellings in online news headlines
}

\author{
JONAS NYGAARD BLOM AND MICHAEL EJSTRUP
}

Language users often have a low tolerance of misspellings and downgrade not only texts with misspellings, but also the writers who make the mistakes. This applies to news articles and journalists as well. In this paper, we present the results from an online experiment from 2018 ( $N=1.502$ participants). In the experiment, the participants have identified misspellings in Danish news headlines and assessed them. The results show that participants have a low tolerance of basic types of misspellings that are often mentioned in the prescriptive literature and normative debate in Denmark and are regarded as reoccurring and typical mistakes. Most of the participants do not assess the misspellings as difficult to understand except for typos. In addition, the semantic domain of the misspelled word only plays a partial role in the downgrading. The most remarkable result shows that many of the participants have a low intolerance of misspellings as well as proper spelling. Thus, it seems that journalists run the risk of readers finding it annoying and even comical when they spell words in accordance with the official norm.

KEYWORDS: orthography, language attitudes, journalism, news headlines 